\title{
Curcumin ameliorates DSS-induced colitis in mice by regulating the Treg/Th17 signaling pathway
}

\author{
CHENG WEI $^{1 *}$, JIAN-YAO WANG $^{2 *}$, FENG XIONG $^{1 *}$, BEN-HUA WU $^{1 *}$, MING-HAN LUO $^{1}$, \\ ZHI-CHAO YU ${ }^{1}$, TING-TING LIU ${ }^{1}$, DE-FENG LI ${ }^{1}$, QI TANG ${ }^{1}$, YING-XUE LI ${ }^{1}$, DING-GUO ZHANG ${ }^{1}$, \\ ZHENG-LEI XU ${ }^{1}$, HONG-TAO JIN ${ }^{1}$, LI-SHENG WANG ${ }^{1}$ and JUN YAO ${ }^{1}$ \\ ${ }^{1}$ Department of Gastroenterology, Jinan University of Second Clinical Medical Sciences, \\ Shenzhen Municipal People's Hospital, Shenzhen, Guangdong 518020; ${ }^{2}$ Department of General Surgery, \\ Shenzhen Children's Hospital, Shenzhen, Guangdong 518026, P.R. China
}

Received August 21, 2018; Accepted September 19, 2019

DOI: $10.3892 / \mathrm{mmr} .2020 .11672$

\begin{abstract}
Curcumin has a therapeutic effect on ulcerative colitis, but the underlying mechanism has yet to be elucidated. The aim of the present study was to clarify the possible mechanisms. Dextran sulfate sodium-induced colitis mice were treated with curcumin via gavage for 7 days. The effects of curcumin on disease activity index (DAI) and pathological changes of colonic tissue in mice were determined. Interleukin (IL)-6, IL-10, IL-17 and IL-23 expression levels were measured by ELISA. Flow cytometry was used to detect the ratio of mouse spleen regulatory T cells (Treg)/Th17 cells, and western blotting was used to measure the nuclear protein hypoxia inducible factor (HIF)- $1 \alpha$ level. The results demonstrated that curcumin can significantly reduce DAI and spleen index scores and improve mucosal inflammation. Curcumin could also regulate the re-equilibration of Treg/Th17. IL-10 level in the colon was significantly increased, while inflammatory cytokines IL-6, IL-17 and IL-23 were significantly reduced following curcumin treatment. No significant difference in HIF-1 $\alpha$ was observed between the colitis and the curcumin group. It was concluded that oral administration of curcumin can effectively treat experimental colitis by regulating the re-equilibration of Treg/Th17 and that the regulatory mechanism may be closely related to the IL-23/Th17 pathway. The results of the present study provided molecular insight into the mechanism by which curcumin treats ulcerative colitis.
\end{abstract}

Correspondence to: Professor Jun Yao or Professor Li-Sheng Wang, Department of Gastroenterology, Jinan University of Second Clinical Medical Sciences, Shenzhen Municipal People's Hospital, 1017 East Gate Road, Shenzhen, Guangdong 518020, P.R. China

E-mail: yj_1108@126.com

E-mail: wangls168@163.com

${ }^{*}$ Contributed equally

Key words: curcumin, $\mathrm{T}$ helper 17 cells, $\mathrm{T}$ regulatory cells, inflammatory bowel disease

\section{Introduction}

The incidence of ulcerative colitis (UC) has recently increased (1). UC is a chronic, non-specific inflammatory disease that affects the colorectal tissue of the body (2). The abnormal immune system in the intestinal mucosa leads to an imbalance in immune cells and inflammatory cytokines, resulting in damage to the intestinal tissues $(3,4)$. Th17 cells have been considered to be closely correlated with inflammatory bowel disease (5), and studies $(6,7)$ have found that there is abnormal mucosal immune response in the intestine of UC, which may be closely related to the imbalance between regulatory $\mathrm{T}$ cells (Treg) and Th17 cells (8). Th17 affects innate and adaptive immune responses, and participates in the immunopathological process and prognosis of inflammatory bowel disease (IBD) by releasing interleukin (IL)-17 and other inflammatory cytokines (9). Previous studies have shown that severe Treg/Th17 imbalance in colitis mice has a clear correlation with the occurrence and development of colitis $(10,11)$. The imbalance of Treg/Th17 and cytokines, such as IL-10, IL-17, IL-6 and IL-23 have a crucial role in the development of UC $(12,13)$. The IL-23/Th17 pathway also plays an important role in the activation of Th17 cells and the release of IL-17 and other inflammatory factors (14). The hypoxia inducible factor (HIF)-1 $\alpha$ signaling pathway plays an important role in the development and activation of Th17 cells and other inflammatory factors, such as IL-17. HIF-1 $\alpha$ can also bind to forkhead box P3 (Foxp3), leading to accelerated degradation of Foxp3 and affecting the development and function of Treg (15). Recently, the abnormal Treg/Th17 ratio has become one of the possible targets for IBD therapy $(16,17)$. Curcumin is a non-toxic all-natural compound extracted from turmeric and has many biological activities such as anti-inflammation, anti-infection, anti-coagulation and immune regulation $(15,18)$. It has been reported that curcumin has a good therapeutic effect on experimental colitis in mice and can alleviate intestinal inflammation. It participates in anti-inflammatory, anti-oxidation and other protective effects by reducing the concentration of nitric oxide, myeloperoxidase and tumor necrosis factor (TNF)- $\alpha$, and inhibiting the activation of $\mathrm{NF}-\kappa \mathrm{B}$. However, its therapeutic mechanism in UC remains 
to be elucidated $(8,19,20)$. Through animal experiments, the therapeutic effect of curcumin on mice with colitis was studied at the histopathological, cytological and molecular levels, with the objective of revealing the possible mechanism of curcumin on mice with colitis and providing clinical treatment ideas. The results of the present study demonstrated that oral administration of curcumin to dextran sulfate sodium (DSS)-treated mice could inhibit the intestinal inflammation, and increase the levels of anti-inflammatory cytokines IL-10 by regulating the balance of Treg/Th17, while reducing the concentration of proinflammatory cytokines IL-23, IL-17, and IL-6. It achieved therapeutic effect through the inhibition of the IL-23/Th17 pathway (but possibly not the HIF-1 $\alpha$ signaling pathway).

\section{Materials and methods}

Experimental animal and treatment. SPF grade BALB/c male mice (6-7 weeks old, weight 22-26 g, n=36; Laboratory Animal Center of Southern Medical University, certificate number: SCXK Guangdong, China) were reared in a clean animal room. The temperature was $22-25^{\circ} \mathrm{C}$ and the relative humidity was $\sim 55 \%$. The environment was a $12-\mathrm{h}$ light/dark cycle. Water was given as required and mice were given free access to food. DSS (average molecular weight 5,000; FUJIFILM Wako Pure Chemical Corporation) was formulated as 5\% solution using sterile distilled water. Curcumin was purchased from Guangzhou QiYun Biotechnology Co., Ltd., (purity $\geq 98.5 \%$ ). The mice were fed adaptively for one week and randomly divided into three groups with 12 in each group: Normal group, Colitis control group and Curcumin $100 \mathrm{mg} / \mathrm{kg}$.d treatment group (CUR group). The Normal group was given sterile distilled water for 14 days. The Colitis group and the CUR group were given 5\% DSS for 7 days. Once the model was established, they were given distilled water for 7 days. On the 8th day, mice in the Normal group and the Colitis group were given $0.2 \mathrm{ml}$ of $0.5 \%$ ethanol per day for 7 days, while mice in the CUR group were given (via gavage) the dose of curcumin $100 \mathrm{mg} / \mathrm{kg}$.d in $0.2 \mathrm{ml}$ of $0.5 \%$ ethanol for 7 days. All experiments on animals were approved by the Experimental Animal Ethics Committee of Southern Medical University.

Evaluation of experimental colitis in mice. Mouse daily disease activity index (DAI) was recorded according to the Murthy scoring system (21). The scoring criteria are shown in Table I. DAI = (weight loss rate, stool viscosity, and total score of invisible/visible bloody stools)/3). After the mice were sacrificed, the spleen was dissected and the blood on the spleen surface was washed with physiological saline, blotted, and weighed. Spleen weight $(\mathrm{mg}) /$ body weight $(\mathrm{g})$ indicates spleen index (SI) (22).

Histopathology evaluation of mouse colon. Fresh colon tissue (without cecum) of each experimental group was collected and immediately placed in $10 \%$ formaldehyde. After fixing at room temperature for $48 \mathrm{~h}$, the tissues were dehydrated using an ascending alcohol series at room temperature: $30 \%$ ethanol for $40 \mathrm{~min}, 50 \%$ ethanol for $40 \mathrm{~min}, 70 \%$ ethanol for $30 \mathrm{~min}$, $80 \%$ ethanol for $30 \mathrm{~min}, 90 \%$ ethanol for $30 \mathrm{~min}, 95 \%$ ethanol for $30 \mathrm{~min}, 95 \%$ ethanol for $30 \mathrm{~min}, 100 \%$ ethanol for $20 \mathrm{~min}$ and $100 \%$ ethanol for $20 \mathrm{~min}$. Subsequently, the tissue sections were cut into $5-\mu \mathrm{m}$ thick sections and heated at $60^{\circ} \mathrm{C}$ for $55 \mathrm{~min}$. Then the tissues sections were embedded in paraffin and hematoxylin and eosin (H\&E) staining was performed as follows: Hematoxylin for $10 \mathrm{~min}$ at room temperature and eosin for $2 \mathrm{~min}$ at room temperature All tissue sections were observed under a BX-51 light microscope (Olympus Corporation; magnification, $\mathrm{x} 200$ ).

Flow cytometry detection of Treg/Th17 cells. The spleen of the mouse was removed from the laminar flow cabinet, and the appropriate amount of spleen tissue was taken. Subsequently, $5 \mathrm{ml}$ mouse lymphocyte separation solution was added to separate the lymphocytes, and the number of lymphocytes was adjusted to $2 \times 10^{6} /$ tube. Samples were prepared according to the manufacturer's protocol of Th17/Treg kit (BD Biosciences). Lymphocytes were stimulated with $50 \mathrm{ng} / \mathrm{ml}$ phorbol 12-myristate 13-acetate (PMA; Sigma-Aldrich; Merck KGaA), $1 \mu \mathrm{g} / \mathrm{ml}$ ionomycin (Sigma-Aldrich; Merck KGaA) and appropriate concentration of Monensin (BD Biosciences) for $5 \mathrm{~h}$. Cells were collected and incubated at room temperature for 30 min with $20 \mu \mathrm{l}$ flow antibody in each tube after staining, fixation, membrane breaking and other steps. The main flow antibodies included mouse CD4-PerCP-Cy5.5, IL-17A-PE, and Alexa Fluor 647-FoxP3. A negative control group was also included. Samples were analyzed by flow cytometry using a BD FACSCalibur flow cytometer (BD Biosciences) and FACStation software (version FACS101; BD Biosciences).

ELISA assay for cytokine expression. A total of $50 \mathrm{mg}$ of mouse colon tissue was collected and an appropriate amount of pre-cooled saline was added. Following homogenization with a glass homogenizer on ice, it was centrifuged at low temperature, and the supernatant was collected for quantification of the protein with Nanodrop 2000 (Thermo Fisher Scientific, Inc.). The concentrations of IL-6 (cat. no. DKW12-2060; Dakewe Biotech Co., Ltd.), IL-10 (DKW12-2100; Dakewe Biotech Co., Ltd.), IL-17 (DKW12-2170; Dakewe Biotech Co., Ltd.), and IL-23 (cat. no. M2300; R\&D Systems, Inc.) in the intestine of mice were measured in strict accordance with the ELISA kit instructions.

Western blotanalysis. A total of $100 \mathrm{mg}$ of colon tissue was taken, and the nuclear protein was extracted using theNE-PER ${ }^{\mathrm{TM}}$ Nuclear and Cytoplasmic Extraction Reagents kit (Pierce; Thermo Fisher Scientific, Inc.), protease and phosphatase inhibitors were added. Protein quantification was performed by using Nanodrop 2000 quantitative analyzer (Thermo Fisher Scientific, Inc.) and the BCA method. An appropriate amount of loading buffer was added to adjust to the same concentration. Then $10 \%$ protein electrophoresis separation gel and 5\% aminated gel were prepared, and $30 \mu \mathrm{g}$ nuclear protein was sampled. After the electrical conversion, the PVDF membrane was removed and blocked in $5 \%$ skimmed milk powder/TBST solution $(0.05 \%$ Tween-20) for $1 \mathrm{~h}$ at room temperature. The samples were separated by electrophoresis, followed by membrane transfer, blocking, primary and secondary antibodies incubation, ECL imaging (Thermo Fisher Scientific, Inc.), and analysis. The primary antibodies were anti-mouse HIF-1 $\alpha$ (cat. no. 36169S; 1:200; Cell Signaling Technology, Inc.) and Lamin (cat. no. ABP0099; 1:1,500 dilution; Abbkine Scientific Co., Ltd.), and the incubation was at $4^{\circ} \mathrm{C}$ 
Table I. Murthy scoring system.

\begin{tabular}{lccc}
\hline Score & Weight loss rate & Stool viscosity & Invisible/visible bloody stools \\
\hline 0 & $(-)$ & Normal (Granular, shaped) & Normal \\
1 & $1-5 \%$ & Soft (paste, no adhesion to the anus) & Occult blood (+) \\
2 & $6-10 \%$ & & Bloody stools \\
3 & $11-15 \%$ & Diarrhea (water sample, adhesion to the anus) & \\
4 & $>15 \%$ & & \\
\hline
\end{tabular}

overnight. The secondary antibodies for horseradish peroxidase labeled goat anti mouse (cat. no. 79233; 1:1,500 dilution, OriGene Technologies, Inc.) incubated for $1 \mathrm{~h}$ at room temperature. Quantity One software (v1-D; Bio-Rad Laboratories, Inc.) was used to calculate the relative grayscale value with Lamin as the reference protein. SPSS v13.0 statistical software (SPSS, Inc.) was used for statistical analysis.

Statistical analysis. The experimental data were all expressed as mean \pm standard deviation. All experimental data were analyzed using SPSS v13.0 statistical software (SPSS, Inc.). One-way analysis of variance was used to analyze the differences between groups. S-N-K (Student-Newman-Keuls, q test) was selected to compare the mean of multiple samples. $\mathrm{P}<0.05$ was considered to indicate a statistically significant difference.

\section{Results}

DAI and SI in mice. No animal died during the experiment. The Normal group score was 0 . Colitis group and CUR group demonstrated umbelliferous bloody stool, weight loss, and activity decreased in the first $7 \mathrm{~d}$ after administration of 5\% DSS. As shown in Fig. 1A, compared with the Colitis group, the DAI score was significantly lower in the CUR group on the 10 to 14 th day $(\mathrm{P}<0.05)$. As shown in Fig. $1 \mathrm{~B}$ and $\mathrm{C}$, the spleen was significantly enlarged in the Colitis group, while the CUR group spleen decreased significantly and SI decreased compared with the Colitis group $(\mathrm{F}=71.85, \mathrm{P}<0.05)$.

Mucosal inflammation. As shown in Fig. 2, compared with the Normal group (Fig. 2A-a), the Colitis group (Fig. 2A-b) clearly demonstrated an acute inflammatory response with mucosal erosion, congestion, edema, reduction of crypts and infiltration of inflammatory cells such as neutrophils. Compared with the Colitis group, mucosal inflammatory cell infiltration, erosion and edema in the CUR group (Fig. 2A-c) were significantly improved.

Treg/Th17 cell ratios. As shown in Fig. 3, compared with the Normal group, the ratio of CD4+IL-17+(Th17)/CD4+ lymphocytes was significantly increased in the Colitis group, The Treg/Th17 ratio was the lowest $(\mathrm{P}<0.05)$. Compared with the Colitis group, Th17 lymphocytes in the CUR group were significantly decreased, and the Treg/Th17 ratio was significantly increased with the Colitis group $(\mathrm{F}=30.67, \mathrm{P}<0.05)$.

Alterations to cytokine levels. As shown in Fig. 4, compared with the Normal group, the levels of cytokines IL-6, IL-17,
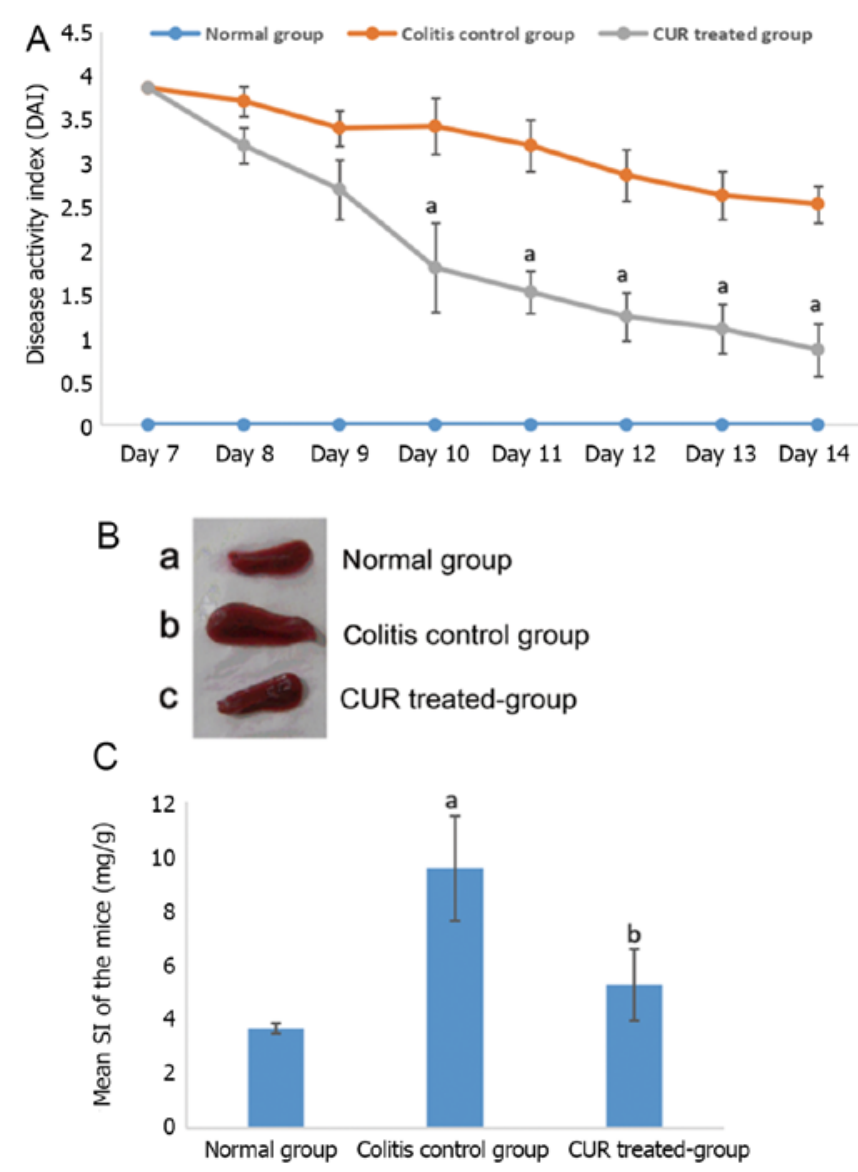

Figure 1. Effects of CUR on disease activity index and mean SI in mice. (A) Disease activity index. (B) Mean SI in the (B-a) normal group, (B-b) colitis control group and (B-c) CUR-treated group. (C) Analysis of mean SI. ${ }^{\mathrm{a}} \mathrm{P}<0.05$ vs. normal group and ${ }^{\mathrm{b}} \mathrm{P}<0.05$ vs. colitis control group. CUR, curcumin; SI, spleen index.

and IL-23 in the colon of mice from the Colitis group were significantly increased, while the IL-10 cytokine level was significantly decreased $(\mathrm{F}=67.96, \mathrm{P}<0.05)$. Compared with the Colitis group, the IL-6, IL-17 and IL-23 in the colon of the CUR group were significantly decreased, while IL-10 was significantly elevated $(\mathrm{F}=21.36, \mathrm{P}<0.05)$.

Alterations to HIF-1 $\alpha$ protein. As shown in Fig. 5, compared with the Colitis group and the CUR group, the expression of HIF-1 $\alpha$ in the colon tissue of the normal group was significantly decreased $(\mathrm{F}=52.18, \mathrm{P}<0.05)$. The expression of the nuclear protein HIF-1 $\alpha$ in the colon mucosa in the Colitis group and the CUR group was significantly different $(\mathrm{F}=12.35, \mathrm{P}<0.05)$. 

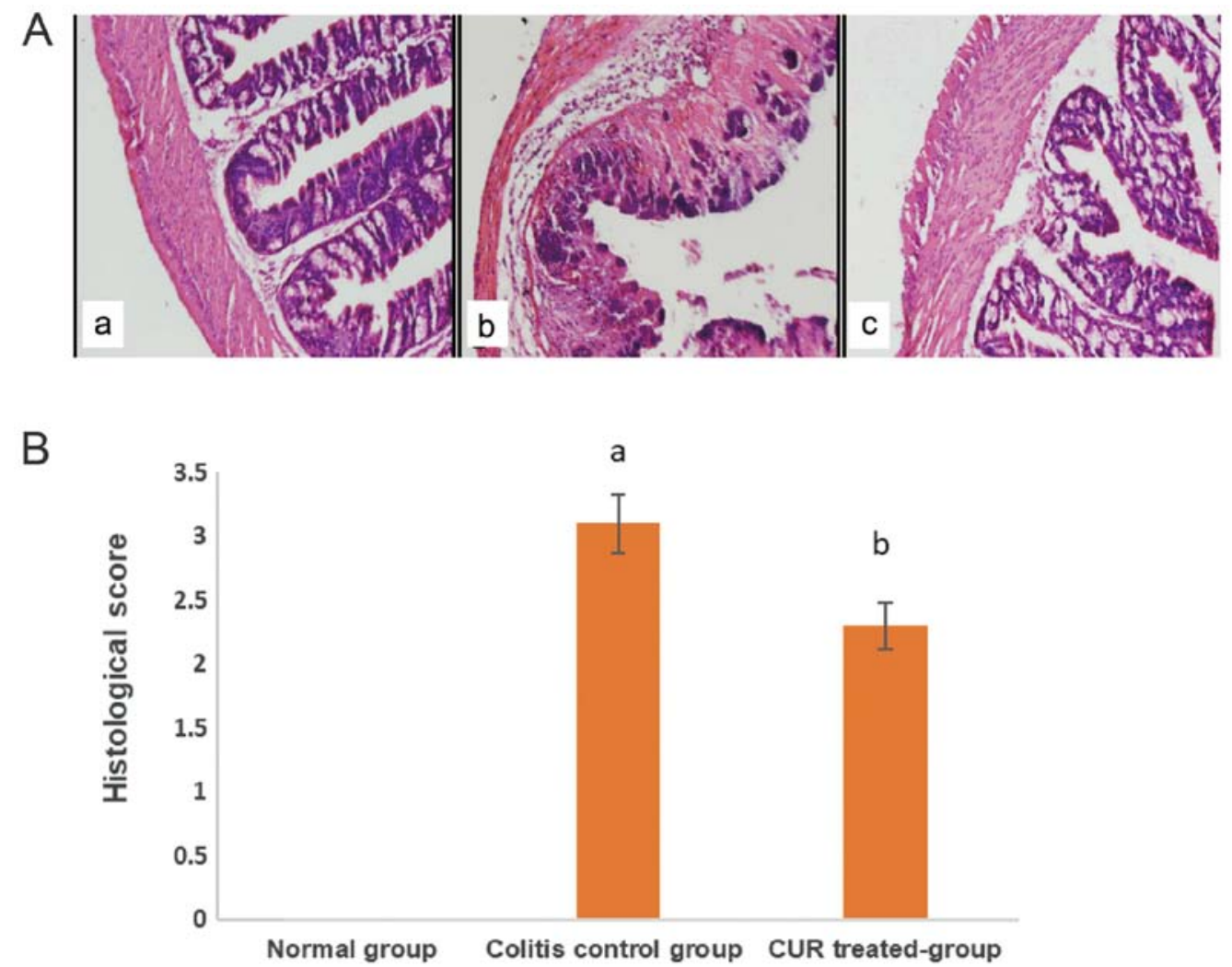

Figure 2. Effects of CUR on histological score of distal colon in mice. (A) Histological examination of colon (magnification, x100) in the (A-a) normal group, (A-b) colitis control group and (A-c) CUR-treated group. (B) Analysis of histological score ${ }^{\mathrm{a}} \mathrm{P}<0.05$ vs. normal group and ${ }^{\mathrm{b}} \mathrm{P}<0.05$ vs. colitis control group. CUR, curcumin.

\section{Discussion}

The present study observed increasing DAI and SI and severe mucosa erosion in colitis mice, which is similar to the symptoms of humans UC. After 7 days of curcumin treatment in experimental colitis mice, DAI and SI were significantly decreased, and colonic mucosal inflammation was significantly improved, suggesting that curcumin has a good therapeutic effect on mice with colitis. Previous studies have achieved similar therapeutic effects on colitis mice (23-25). One of the problems with curcumin in the treatment of colitis is low gastrointestinal absorption, however, IBD is a special case because curcumin does not need to be absorbed through the gastrointestinal tract to trigger a systemic therapeutic effect, but rather serves a therapeutic role through direct intestinal contact. Curcumin can significantly control the symptoms of systemic disease and intestinal inflammation in colitis mice by improving the DAI and intestinal pathology of colitis mice. The effect of curcumin on the spleen of mice attracted our attention, and thus the underlying immune mechanisms that are associated with the therapeutic effect of curcumin were further explored.

It was demonstrated that the CUR group had more significant improvement in DAI and SI compared with the colitis group. The ratio of Th17 cells increased significantly in splenic lymphocytes of colitis mice, suggesting that there was a serious imbalance in Treg/Th17 ratio in colitis. DSS-induced colitis mice experienced a disruption in Treg/Th17 balance, which led to intestinal immune disorders, one of the key factors for the formation and progression of colitis. It was thus speculated that that the spleen serves as an important immune organ and that DSS can induce immunological disorders in colitis mice and cause compensatory enlargement of the spleen. The present study further confirmed that there was a significant Treg/Th17 imbalance in the splenic lymphocytes of mice with colitis, which is consistent with human UC. Th17-related cytokines IL-6, IL-17 and IL-23 in mice with colitis was also increased, while Treg-related cytokine IL-10 was significantly decreased.

It was speculated that there were multiple mechanisms that could mediate the therapeutic effect of curcumin on colitis. First, the imbalance of Treg/Th17 occurs in a variety of inflammatory and autoimmune diseases. The present study confirmed that curcumin primarily regulates Treg/Th17 rebalance by downregulating CD4+IL-17+Th17 cells $(26,27)$. Therefore, it was hypothesized that one of the mechanisms for the therapeutic effect of curcumin in the treatment of IBD is to regulate the re-balance of Treg/Th17. The experiments also revealed that the mechanism of curcumin in regulating Treg/Th17 re-balance may be through the inhibition of the IL-23/Th17 pathway (but possibly not the HIF-1 $\alpha$ signaling pathway) to downregulate of Th17. The present study demonstrated that curcumin can significantly downregulate Th17 cells. In addition, the expression of IL-23 in intestinal tissue was significantly decreased in CUR group. Therefore, it is suggested that the main mechanism of curcumin regulation of Treg/Th17 rebalance is to inhibit the IL-23/Th17 pathway. It has also been shown by previous studies that the IL-23/Th17 pathway is closely related to the development and activation 

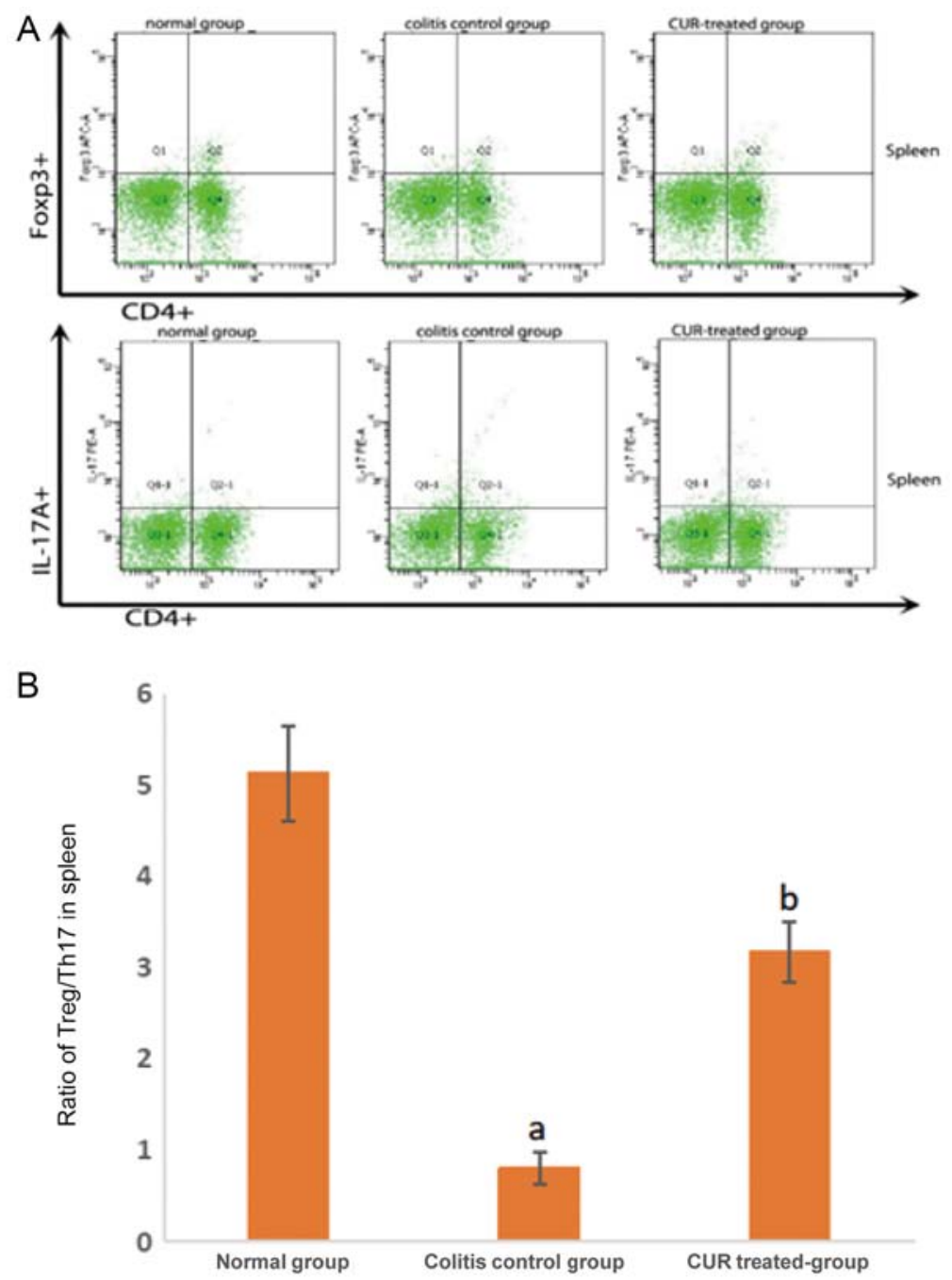

Figure 3. Effects of CUR on Treg/Th17 in the spleen. The ratio of Treg/Th17 in spleen in normal group, colitis control group and CUR-treated group was (A) determined by flow cytometry and (B) quantified. ${ }^{\mathrm{P}} \mathrm{P}<0.05$ vs. normal group and ${ }^{\mathrm{b}} \mathrm{P}<0.05$ vs. colitis control group. CUR, curcumin; CD4, cluster of differentiation 4; Foxp3, forkhead box P3; IL, interleukin; Treg, regulatory T cells.

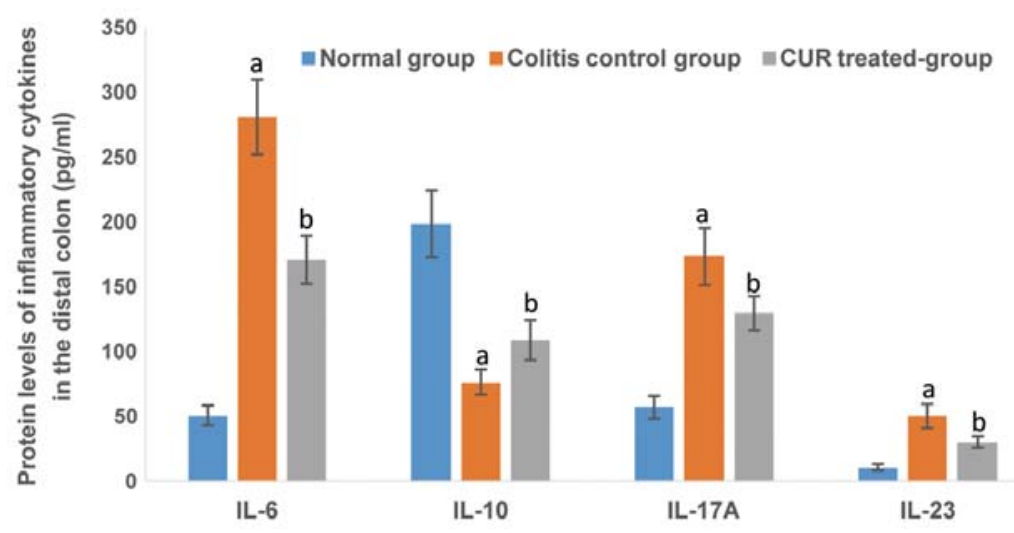

Figure 4. Effects of CUR on cytokine protein levels. Cytokine protein levels in normal group, colitis control group and CUR-treated group. ${ }^{\mathrm{a}} \mathrm{P}<0.05$ vs. normal group and ${ }^{\mathrm{b}} \mathrm{P}<0.05$ vs. colitis control group. CUR, curcumin; IL, interleukin.

of Th17 cells, and thus is associated with various diseases such as chronic inflammatory diseases and immune diseases, including rheumatoid arthritis, psoriasis and IBD (28-30). However, studies have suggested that local tissue hypoxia induces HIF-1 $\alpha$ synthesis, promotes its entry into the nucleus to exert biological functions, upregulates and activates Th17, and simultaneously promotes Foxp3 binding (leading to its ubiquitin and degradation) and downregulates and inhibits Treg $(31,32)$. The present study found that curcumin produced no significant downregulation of the colon nuclear 
A
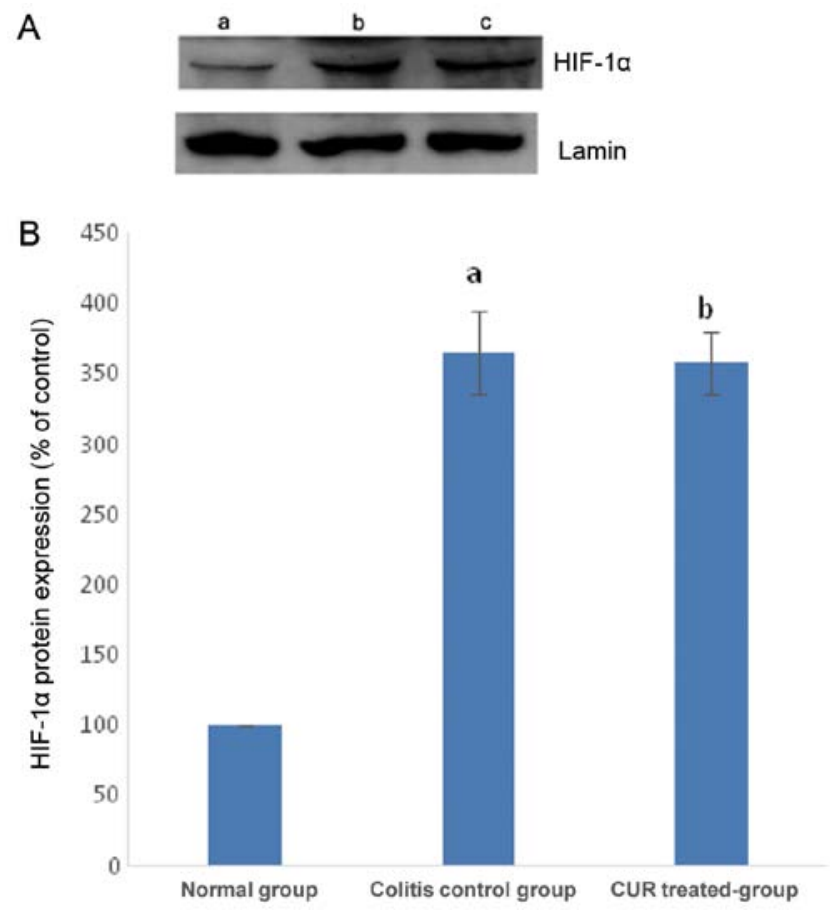

Figure 5. Effects of curcumin on HIF-1 $\alpha$ protein expression. (A) HIF-1 $\alpha$ protein expression in the (a) normal group, (b) colitis control group and (c) CUR-treated group. (B) Protein expression was semi-quantified. ${ }^{a} \mathrm{P}<0.05$ vs. normal group and ${ }^{b} \mathrm{P}>0.05$ vs. colitis control group. CUR, curcumin; HIF, hypoxia inducible factor.

protein HIF-1 $\alpha$. Thus, it is hypothesized that CUR may not participate in regulating cell balance by inhibiting the HIF-1 $\alpha$ signaling pathway.

The present study demonstrated that the anti-inflammatory cytokine IL-10 in the CUR treatment group was elevated, and the proinflammatory cytokines IL-6, IL-17, and IL-23 were decreased. Therefore, maintaining the re-equilibration of cytokines serves an important role in curcumin treatment of IBD. IL-10 plays a negative regulatory role in cellular immunity. It can inhibit the antigen presentation and downregulate the transcription and secretion of IL-1 $\beta$, IL- 6 and TNF- $\alpha$ and other inflammatory factors in $\mathrm{T}$ cells and macrophages. Ultimately, it inhibits T cell-mediated immune response and thus improves UC intestinal inflammation (4). Curcumin serves an anti-inflammatory role by elevating the level of IL-10 and reducing pro-inflammatory cytokines. It was speculated that curcumin promotes the proliferation of antigen-specific effector cells by modulating the interaction between immune cells through the regulation of multiple cytokines, and thus improves the local intestinal or systemic inflammatory response and balances immune disorders in mice with colitis $(33,34)$.

Curcumin is an all-natural compound extracted from plants. It has many biological activities including anti-inflammatory, anti-infective and immune-regulating, and it protects the intestinal mucosa and repairs the function of intestinal tissue $(35,36)$. Other similar studies have shown that in the DSS-induced colitis model, curcumin is found to significantly improve intestinal inflammation, repair the intestinal mucosa and inhibit the expression of TNF- $\alpha$ and p38MAPK $(23,24)$.

Curcumin itself has anti-inflammatory and anti-infective effects. By inhibiting production of leukocyte eicosanoid and related inflammatory cytokines, Treg/Th17 disorder is balanced. Through negative feedback regulation of its own immune and anti-inflammatory system, it further prevented the inflammatory cascade amplification, which serves a crucial role in the recovery of UC. At the same time, curcumin can reduce and inhibit the exudation of neutrophils and macrophages, regulate intestinal immune disorders, reduce intestinal endothelial cell swelling and increase permeability, which further reduces intestinal inflammation $(4,37)$.

Therefore, the present study suggested that the mechanism of curcumin in treating IBD may be through downregulating the proportion of Th17 cells to regulate the re-equilibration of Treg/Th17 and Th17-related cytokines. Curcumin can significantly decrease the DAI and SI of the mice with colitis. It can regulate the re-equilibration of Treg/Th17 by inhibiting the IL-23/Th17 pathway, downregulating IL-6, IL-17, IL-23 and upregulating anti-inflammatory cytokine IL-10. Curcumin, as a good all-natural drug for the treatment of IBD, possesses good prospects in clinical application.

\section{Acknowledgements}

The authors would like to thank Dr De-Feng Li, Dr Yao Jun and Dr Wang Lisheng (all Department of Gastroenterology, Jinan University of Second Clinical Medical Sciences, Shenzen Municipal People's Hospital, Shenzhen, Guangdong) for providing project funding support and revising the manuscript.

\section{Funding}

The study was supported by Three Engineering Training Funds in Shenzhen (grant no. SYLY201718) and Technical Research and Development Project of Shenzhen (grant nos. JCYJ20170307100538697, JCYJ20150403101028164, JCYJ20170307100911479 and JCYJ20160429174927286).

\section{Availability of data and materials}

The datasets used and/or analyzed during the present study are available from the corresponding author on reasonable request.

\section{Authors' contributions}

CW designed the study and wrote the manuscript. JW and DL were laboratory personnel; these authors participated in part of the experimental process, guided part of the experimental process design and data analysis, and modified the paper. FX, BW, ML, ZY and HJ performed the histological assessments and evaluations. TL, QT, YL, DZ and ZX performed the flow cytometry and proteomics experiments. LW and JY were responsible for designing the project, guiding the experimental process, revising the paper and providing scientific research funding support. All authors read and approved the final manuscript.

\section{Ethics approval and consent to participate}

All experiments on animals were approved by the Experimental Animal Ethics Committee of Southern Medical University, China. 


\section{Patient consent for publication}

Not applicable.

\section{Competing interests}

The authors declare that they have no competing interests.

\section{References}

1. Ng SC,Shi HY,HamidiN, UnderwoodFE, Tang W, BenchimolEI, Panaccione R, Ghosh S, Wu JCY, Chan FKL, et al: Worldwide incidence and prevalence of inflammatory bowel disease in the 21st century: A systematic review of population-based studies. Lancet 390: 2769-2778, 2018.

2. Lichtenstein GR and Rutgeerts P: Importance of mucosal healing in ulcerative colitis. Inflamm Bowel Dis 16: 338-346, 2010.

3. Monteleone I, Pallone F and Monteleone G: Th17-cytokine blockers as a new approach for treating inflammatory bowe disease. Ann Med 43: 172-178, 2011.

4. Hardenberg G, Steiner TS and Levings MK: Environmental influences on $\mathrm{T}$ regulatory cells in inflammatory bowel disease. Semin Immunol 23: 130-138, 2011.

5. Wu W, Chen F, Liu Z and Cong Y: Microbiota-specific Th17 Cells: Yin and Yang in regulation of inflammatory bowel disease. Inflamm Bowel Dis 22: 1473-1482, 2016.

6. Cho J, Kim S, Yang DH, Lee J, Park KW, Go J, Hyun CL, Jee Y and Kang KS: Mucosal immunity related to $\mathrm{FOXP}^{+}$regulatory $\mathrm{T}$ cells, Th17 cells and cytokines in pediatric inflammatory bowel disease. J Korean Med Sci 33: e336, 2018.

7. Martini E, Krug SM, Siegmund B, Neurath MF and Becker C: Mend your fences: The epithelial barrier and its relationship with mucosal immunity in inflammatory bowel disease. Cell Mol Gastroenterol Hepatol 4: 33-46, 2017.

8. Yao J, Wang JY, Lai MG, Li YX, Zhu HM, Shi RY, Mo J, Xun AY, Jia CH, Feng JL, et al: Treatment of mice with dextran sulfate sodium-induced colitis with human interleukin 10 secreted by transformed Bifidobacterium longum. Mol Pharm 8: 488-497, 2011

9. Sugimoto K, Hanai H, Tozawa K, Aoshi T, Uchijima M, Nagata T and Koide Y: Curcumin prevents and ameliorates trinitrobenzene rsulfonic acid-induced colitis in mice. Gastroenterology 123: 1912-1922, 2002.

10. Yao J, Wei C, Wang JY, Zhang R, Li YX and Wang LS: Effect of resveratrol onTreg/Th17 signaling and ulcerative colitis treatment in mice. World J Gastroenterol 21: 6572-6581, 2015.

11. Zhang DG, Wei C, Yao J, Cai XY and Wang LS: Interleukin-10 gene-carrying bifidobacteria ameliorate murine ulcerative colitis by regulating regulatory T cell/T helper 17 cell pathway. Exp Biol Med (Maywood) 240: 1622-1629, 2015.

12. Eastaff-Leung N, Mabarrack N, Barbour A, Cummins A and Barry S: Foxp3(+) regulatory T cells, Th17 effector cells, and cytokine environment in inflammatory bowel disease. J Clin Immunol 30: 80-89, 2010

13. Ogino $\mathrm{H}$, Nakamura $\mathrm{K}$, Ihara $\mathrm{E}$, Akiho $\mathrm{H}$ and Takayanagi $\mathrm{R}$ : CD4(+)CD25(+) regulatory T cells suppress Th17-responses in an experimental colitis model. Dig Dis Sci 56: 376-386, 2011.

14. Carvalho A, Cunha C, Di Ianni M,Pitzurra L, Aloisi T, Falzetti F, Carotti A, Bistoni F, Aversa F and Romani L: Prognostic significance of genetic variants in the IL-23/Th17 pathway for the outcome of T cell-depleted allogeneic stem cell transplantation. Bone Marrow Transplant 45: 1645-1652, 2010.

15. Ukil A, Maity S, Karmakar S, Datta N, Vedasiromoni JR and Das PK: Curcumin, the major component of food flavour turmeric, reduces mucosal injury in trinitrobenzene sulphonic acid-induced colitis. Br J Pharmacol 139: 209-218, 2003.

16. Bogaert S, Laukens D, Peeters H, Melis L, Olievier K, Boon N, Verbruggen G, Vandesompele J, Elewaut D and De Vos M: Differential mucosal expression of Th17-related genes between the inflamed colon and ileum of patients with inflammatory bowel disease. BMC Immunol 11: 61, 2010.

17. Noma T: Helper T cell paradigm: Th17 and regulatory T cells involved in autoimmune inflammatory disorders, pathogen defense and allergic diseases. Nihon Rinsho Meneki Gakkai Kaishi 33: 262-271, 2010
18. Billerey-Larmonier C, Uno JK, Larmonier N, Midura AJ, Timmermann B, Ghishan FK and Kiela PR: Protective effects of dietary curcumin in mouse model of chemically induced colitis are strain dependent. Inflamm Bowel Dis 14: 780-793, 2008.

19. Arafa HM, Hemeida RA, El-Bahrawy AI and Hamada FM: Prophylactic role of curcumin in dextran sulfate sodium (DSS)-induced ulcerative colitis murine model. Food Chem Toxicol 47: 1311-1317, 2009.

20. Deguchi Y, Andoh A, Inatomi O, Yagi Y, Bamba S, Araki Y, Hata K, Tsujikawa T and Fujiyama Y: Curcumin prevents the development of dextran sulfate sodium (DSS)-induced experimental colitis. Dig Dis Sci 52: 2993-2998, 2007.

21. Cooper HS, Murthy SN, Shah RS and Sedergran DJ: Clinicopathologic study of dextran sulfate sodium experimental murine colitis. Lab Invest 69: 238-249, 1993.

22. Wang Y and Zhao Y: Influence of zuoguiyin on antioxidation in blood thymus and spleen index of senile mice. Chinese J Exp Traditional Med Formulae 13: 67-68, 2007.

23. Camacho-Barquero L, Villegas I, Sánchez-Calvo JM, Talero E, Sánchez-Fidalgo S, Motilva V and de la Lastra CA: Curcumin, a curcuma longaconstituent, acts on MAPK p38 pathway modulating COX-2 and iNOS expression in chronic experimental colitis. Int Immunopharmacol 7: 333-342, 2007.

24. Villegas I, Sánchez-Fidalgo $\mathrm{S}$ and de la Lastra CA: Chemopreventive effect of dietary curcumin on inflammation-induced colorectal carcinogenesis in mice. Mol Nutr Food Res 55: 259-267, 2011.

25. Fuss IJ: Is the Th1/Th2 paradigm of immune regulation applicable to IBD? Inflamm Bowel Dis 14 (Suppl 2): S110-S112, 2008.

26. Awasthi A, Murugaiyan G and Kuchroo VK: Interplay between effector Th17 and regulatory T cells. J Clin Immunol 28: 660-670, 2008

27. Lane N, Robins RA, Corne $\mathrm{J}$ and Fairclough L: Regulation in chronic obstructive pulmonary disease: The role of regulatory T-cells and Th17 cells. Clin Sci (Lond) 119: 75-86, 2010.

28. Abraham $\mathrm{C}$ and Cho J: Interleukin-23/Th17 pathways and inflammatory bowel disease. Inflamm Bowel Dis 15: 1090-1100, 2009.

29. Di Cesare A, Di Meglio P and Nestle FO: The IL-23/Th17 axis in the immunopathogenesis of psoriasis. J Invest Dermatol 129: 1339-1350, 2009

30. Wakashin H, Hirose K, Iwamoto I and Nakajima H: Role of IL-23-Th17 cell axis in allergic airway inflammation. Int Arch Allergy Immunol 149 (Suppl 1): S108-S112, 2009.

31. Horiuchi A, Hayashi T, Kikuchi N, Hayashi A, Fuseya C, Shiozawa $\mathrm{T}$ and Konishi I: Hypoxia upregulates ovarian cancer invasiveness via the binding of HIF-1 $\alpha$ to a hypoxia-induced, methylation-free hypoxia response element of S100A4 gene. Int J Cancer 131: 1755-1767, 2012.

32. Chu WF, Wan L, Zhao D, Qu XF, Cai FL, Huo R, Wang N, Zhu J, Zhang C, Zheng F, et al: Mild hypoxia-induced cardiomyocyte hypertrophy via up-regulation of HIF-1 $\alpha$-mediated TRPC signalling. J Cell Mol Med 16: 2022-2034, 2012.

33. Fiocchi C: Inflammatory bowel disease: Etiology and pathogenesis. Gastroenterology 115: 182-205, 1998.

34. Szkaradkiewicz A, Marciniak R, Chudzicka-Strugała I, Wasilewska A, Drews M, Majewski P, Karpiński T and Zwoździak B: Proinflammatory cytokines and IL-10 in inflammatory bowel disease and colorectal cancer patients. Arch Immunol Ther Exp (Warsz) 57: 291-294, 2009.

35. Bandgar BP, Hote BS, Jalde SS and Gacche RN: Synthesis and biological evaluation of novel curcumin analogues as anti-inflammatory, anti-cancer and anti-oxidant agents. Med Chem Res 21: 3006-3014, 2012.

36. Holt PR, Katz S and Kirshoff R: Curcumin therapy in inflammatory bowel disease: A pilot study. Dig Dis Sci 50: 2191-2193, 2005.

37. Shen W and Durum SK: Synergy of IL-23 and Th17 cytokines: New light on inflammatory bowel disease. Neurochem Res 35: 940-946, 2010.

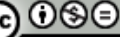

This work is licensed under a Creative Commons Attribution-NonCommercial-NoDerivatives 4.0 International (CC BY-NC-ND 4.0) License. 